\title{
Detection and Monitoring of PAH and Oxy-PAHs by High Resolution Mass Spectrometry: Comparison of ESI, APCI and APPI Source Detection
}

\author{
Thierry Ghislain, Pierre Faure, Raymond Michels \\ G2R, Nancy-Université, CNRS, B.P. 23954506, Vandœuvre-lès-Nancy, France
}

\begin{abstract}
The objective of this work was to compare direct infusion in a Q-TOF mass spectrometer through three different atmospheric pressure sources, electrospray ionization (ESI), atmospheric pressure chemical ionization (APCI), and atmospheric pressure photoionization (APPI) coupled to a high resolution $\mathrm{Q}-\mathrm{TOF}$ mass spectrometer. A complex mixture of $\mathrm{PAH}$ and oxy-PAHs, obtained after the air oxidation of fluoranthene on mineral substrates, was used to compare the different ionization abilities of these sources. Here, we propose analytical methods for the use of all sources. Final goal was to provide background to the choice of the most appropriate source in order to analyze complex organic mixtures as those encountered in polluted soils, water, sediments, as well as in petroleum.
\end{abstract}

Key words: ESI, APCI, APPI, PAH, Oxy-PAH, High molecular mass compounds

\section{Introduction}

$\mathrm{N}$ atural organic matter encountered in rocks, soils, sediments, or water is a complex mixture of organic compounds. This complexity is inherited from the many steps implied in the fate of organic matter in the coupling of the subsurface and geological organic carbon cycles: biosynthesis (type of living organisms), bioproduction (quantities and proportions of organism types), degradation (organic decay), diagenetic processes (organic matter preservation, kerogen formation, burial at depth and heating under geothermal gradient) $[1,2]$.

Organic matter composition thus ranges from mixtures typical of soils (free carbohydrates, lipids, organic acids, humic and fulvic acids...) to fossil organic matter (kerogen, coal) and its transformation products, (petroleum, gas). This complexity led to the development of a large variety of procedures and techniques as to gain chemical information, useful to understand the origin, reactivity, and fate of organic matter in natural systems. Among them, mass

Correspondence to: Thierry Ghislain; e-mail: ghislain@kofo.mpg.de spectrometry allowed significant progress over the last 50 years in the knowledge of organic geochemistry.

One of the latest challenge in the field of mass spectrometry is to be able to characterize and study the fate of the most polar and high molecular mass fractions. While the molecular composition of the lighter and nonpolar molecular mass fractions of solvent soluble compounds is commonly studied by GC-MS techniques, the most polar and high molecular mass fractions (humic and fulvic acids, petroleum asphaltenes for instance) cannot be investigated without significant pretreatment (i.e., derivatization, pyrolysis, stepwise chemical degradation). Coupling with spectroscopic studies were thus privileged (i.e., FTIR, NMR) and led to a description of these high molecular mass entities. These compounds account for most of the solvent soluble organic matter extracted from samples and encountered in petroleum. Recent development in mass spectrometry focused on hyphenated methods combining low energy ionization with ultrahigh resolution mass spectrometry [3].

Low energy ionization sources (ESI, APCI, and APPI) have the advantage to allow the ionization of high molecular 
mass organic compounds (several hundred thousand Daltons for ESI, and between 1500 and $2000 \mathrm{Da}$ for APPI and APCI) with minimum sample treatment (i.e., direct infusion of aqueous or organic solutions). High resolution mass spectrometry allows separation and detection of a very large range of the produced ions to determine mass distributions or to identify specific compounds.

In this very general context, we focused on the origin and fate of polyaromatic hydrocarbons (PAHs) in soils and sediments polluted by the input of coal processing plants. These compounds are known for their high toxicity and carcinogenic properties, and are thus on the priority list of US-EPA. From the perspective of estimating the capacity of natural systems to self-recover over time, our studies consider for the first time the possibility of a new reactive pathway in which PAHs undergo mineral catalyzed low temperature oxidation leading to their immobilization in sediments $[4,5]$.

Our capacity on analyzing and identifying the higher molecular mass reaction products by high resolution mass spectrometry was key in this investigation.

In atmospheric pressure ionization sources, it is commonly accepted that electrospray ionization (ESI) is mainly used for ionic species or for easily ionizable compounds (with a labile hydrogen for instance). Yet, ESI can also be used for the detection of nonpolar compounds when ionization is favored using additives like silver [6] or tropylium [7, 8]. The original work using silver cationization was performed by Hand et al. [6] in solid phase using secondary ion mass spectrometry (SIMS). Then, electron transfer reactions using an oxidant in liquid phase (methylene chloride with trifluoroacetic acid for instance) extended the application field of the ES ionization by allowing the detection of non polar compounds such as PAHs $[9,10]$. More recently, several works investigated the benefit of the use of silver mediated ionization for PAHs [11, 12], for its ability to provoke a Lewis acid-base reaction [13] and mainly create the radical cation $\mathrm{M}^{+\bullet}$ or its binding form $[\mathrm{Ag}+\mathrm{M}]^{+}$.

Other ionization techniques, like atmospheric pressure chemical ionization (APCI) and atmospheric pressure photoionization (APPI) sources are more efficient in the case of nonpolar organic compounds because the principle of the ionization is mainly based on compound ionization energy. For instance, APCI is used for the detection of high molecular mass PAHs [14]. Yet, it is preferentially used coupled to high performance liquid chromatography (HPLC) for PAH quantification $[8,15,16]$.

APPI is known to be more sensitive to nonpolar compounds and especially PAHs compared with APCI and ESI [17]. Yet, better sensitivity is often obtained by the use of dopant.

Thus, different dopants, type of solvents, and flow rates were investigated for the analysis of pure PAHs [18-22].

We present comparative results on the use of electrospray ionization (ESI), atmospheric pressure chemical ionization (APCI), and atmospheric pressure photoionization (APPI) in order to allow the best choice of an ionization source as to identify reaction products from low temperature mineral catalyzed oxidation experiments of pure PAHs [4].

\section{Experimental}

\section{Samples and Chemicals}

The experiments were carried out on PAH oxidation experiments described elsewhere [4]. They consist of the air oxidation at $100{ }^{\circ} \mathrm{C}$ of fluoranthene mixed with various mineral matrices (quartz, clay, limestone) during 2, 4, and 6 mo. A range of high molecular mass compounds were thus created. These compounds are based on fluoranthene units $\left(\mathrm{C}_{16} \mathrm{H}_{10}, 202 \mathrm{~g} \cdot \mathrm{mol}^{-1}\right)$ on which the addition of fluoranthene reactional intermediates $\left(\mathrm{C}_{16} \mathrm{H}_{8}, 200\right.$ g.mol ${ }^{-1}$ or $\mathrm{C}_{16} \mathrm{H}_{8} \mathrm{O}, 216$ g.mol $\left.{ }^{-1}\right)$ lead to higher molecular mass oxy-PAHs such as $\mathrm{C}_{32} \mathrm{H}_{16} \mathrm{O}, \mathrm{C}_{48} \mathrm{H}_{24} \mathrm{O}_{2}$ (respectively 418 and 632 g.mol ${ }^{-1}$ ). In this work, fluoranthene $\left(\mathrm{C}_{16} \mathrm{H}_{10}\right)$ and its derivatives $\left(\mathrm{C}_{32} \mathrm{H}_{16} \mathrm{O}\right.$ and $\mathrm{C}_{48} \mathrm{H}_{24} \mathrm{O}_{2}$ ) are considered in order to compare the ionization procedures using different ionization sources.

The concentration of the sample $\left(77 \mu \mathrm{mol} . \mathrm{mL}^{-1}\right.$ based on fluoranthene quantification) was diluted 100 times in the appropriate solvent for analysis. Pure fluoranthene (Fla) 99.9\% and silver nitrate $\left(\mathrm{AgNO}_{3}\right) \geq 99.9 \%$ were purchased from Sigma-Aldrich Co. (Saint Louis, MO, USA) and was used with no further purification. $n$-Hexane, methanol, chloroform, toluene, (HPLC grade), were purchased from VWR, Int. (Strasbourg, France) and used as received. Silver Nitrate for ESI experiments was diluted in methanol then stirred to complete dissolution. It was added to the sample solution to obtain a final concentration of $100 \mathrm{nM}$ prior to injection in the ionization sources.

\section{Q-TOF Mass Spectrometry}

Mass spectra were recorded on a hybrid quadrupole-time of flight mass spectrometer (Bruker Daltonics, Bremen, Germany) equipped with the different atmospheric pressure sources. All intensities are an average of 60 mass spectra recorded for $1 \mathrm{~min}$ after stabilization of the total ion current (TIC) at $1 \mathrm{spectrum} / \mathrm{s}$ rate.

\section{ESI, APCI, APPI Parameters}

All sources were optimized for the $\mathrm{C}_{48} \mathrm{H}_{24} \mathrm{O}_{2}$ ion $(\mathrm{m} / z$ 632) to perform the best characterization of the mixture and allow comparison of the ionization sources. For ESI source, the capillary voltage was set at $5 \mathrm{kV}$ and $167 \mathrm{~V}$ for cone voltage. Nitrogen gas was maintained at 0.4 bar for nebulization and $4 \mathrm{~L}$. $\min ^{-1}$ at $190^{\circ} \mathrm{C}$ for evaporation. APCI capillary voltage was set at $-2500 \mathrm{~V}$ with a corona discharge at $5 \mu \mathrm{A}$. APPI (Syagen Technology Inc., Tustin, CA, USA), contains a Krypton lamp that produced a $10 \mathrm{eV}$ photon beam operating in positive mode. The source was set at capillary voltage $-4500 \mathrm{~V}$.

Direct injection of the sample solutions was performed using a syringe pump (KD Scientific, Holliston, MA, USA). Flow rate was set at $3 \mu \mathrm{L} \cdot \mathrm{min}^{-1}$ for ESI and $100 \mu \mathrm{L} \cdot \mathrm{min}^{-1}$ for APCI and APPI. 


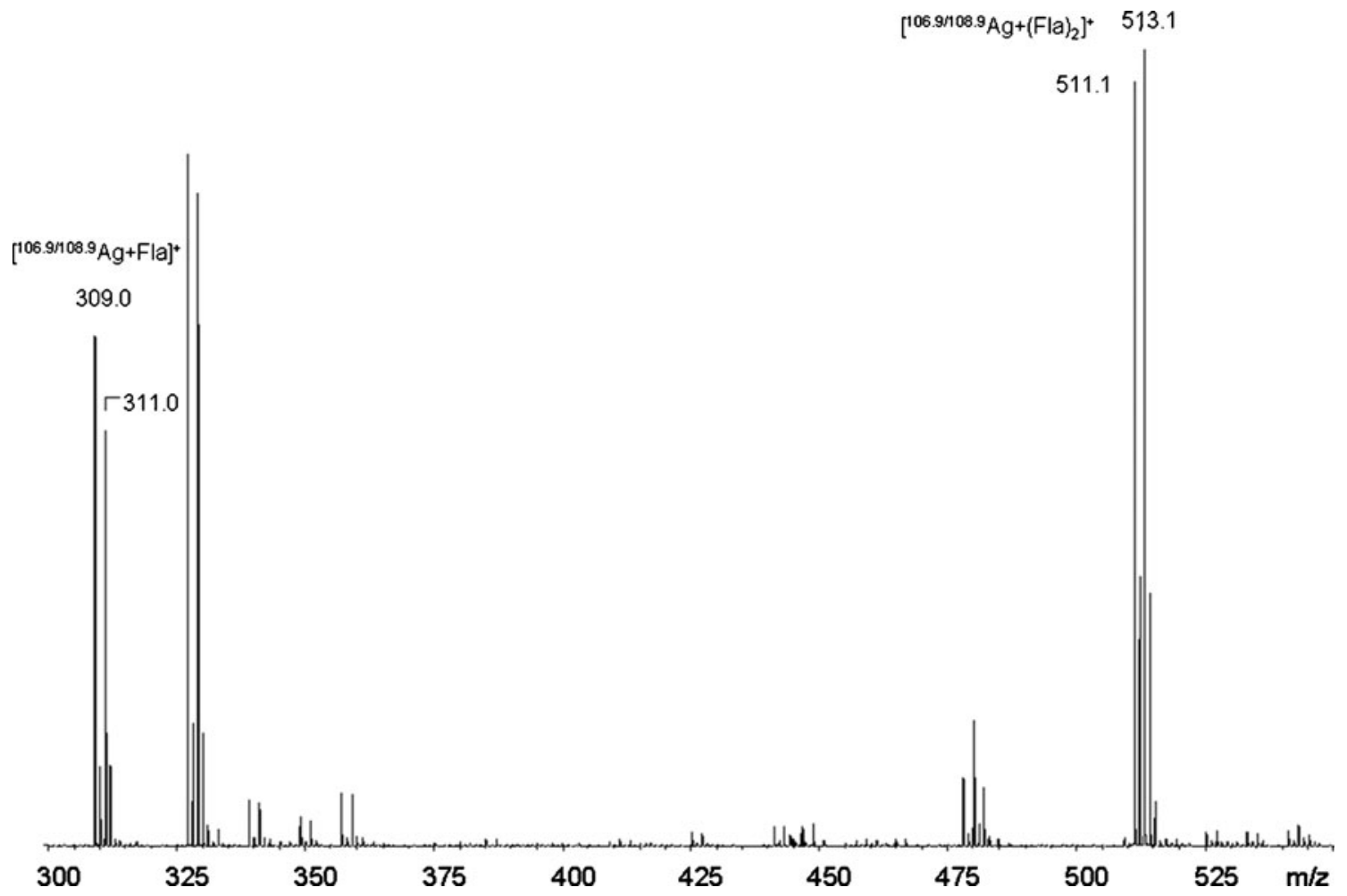

Figure 1. $\mathrm{ESI}+$ mass spectrum of $\mathrm{Ag}(\mathrm{l})$ cationized mixture of $\mathrm{PAH}$ and oxy-PAHs reaction products obtained after oxidation of fluoranthene on limestone at $100{ }^{\circ} \mathrm{C}$ for 4 months

\section{Shared Parameters for APCI and APPI}

Nitrogen gas was maintained at 3 bar for nebulization and $7 \mathrm{~L}$. $\min ^{-1}$ at $250{ }^{\circ} \mathrm{C}$ for evaporation and $450{ }^{\circ} \mathrm{C}$ for vaporizer temperature. In the case of APCI and APPI the flow rate was also tested and in both cases set at $100 \mu \mathrm{L} \cdot \mathrm{min}^{-1}$.

\section{Results}

\section{ESI Source}

Due to its base principle, ESI hardly ionizes non polar compounds [23, 24]. Thus, the ESI source was used using silver ions as ionization mediator (Figure 1), which allows an electrochemical reaction consisting of the transfer of an electron from aromatics to the silver ion according to Equation 1 [11].

$$
\mathrm{PAH}+\mathrm{Ag}(\mathrm{I}) \rightarrow \mathrm{PAH}^{+\bullet}+\mathrm{Ag}(0)
$$

However, other reactions were proposed by $\mathrm{Ng}$ et al. [12] when the silver complex $[\mathrm{Ag}+\mathrm{PAH}]^{+}$is observed and this complex can undergo dissociation according to Equation 2a, $\mathrm{b}$, and $\mathrm{c}$.

$$
[2 \mathrm{PAH}+\mathrm{Ag}]^{+} \rightarrow \mathrm{PAH}+[\mathrm{PAH}+\mathrm{Ag}]^{+}
$$

$$
\begin{gathered}
{[\mathrm{PAH}+\mathrm{Ag}]^{+} \rightarrow \mathrm{PAH}+\mathrm{Ag}(\mathrm{I})} \\
\rightarrow \mathrm{PAH}^{+\bullet}+\mathrm{Ag}(0)
\end{gathered}
$$

In general, the odd-electron radical is observed $\left(\mathrm{M}^{+\bullet}\right)$ when mixing PAHs with silver ions at a high cone voltage [12]. This was observed when we tested pyrene $\left(\mathrm{C}_{16} \mathrm{H}_{10}\right)$ in our system, a result consistent with Hager and Wallace [25]. In the case of fluoranthene, no odd-radical ions were observed, only clusters such as $[\mathrm{Ag}+\mathrm{Fla}]^{+}$and $\left[\mathrm{Ag}+(\mathrm{Fla})_{2}\right]^{+}$at, respectively, $\mathrm{m} / z$ 309/ 311 and 509/511. Maziarz et al. [11] related these phenomena to the ionization energy difference between $\mathrm{Ag}$ and PAHs. When the $\mathrm{Ag}$ ionization energy $(7.57 \mathrm{eV})[26,27]$ is greater

Table 1. Measured Intensities Determined by APCI-QTOF of Different Molecules According to the Solvent Used

\begin{tabular}{llllllr}
\hline & $\mathrm{C}_{16} \mathrm{H}_{10}$ & $\mathrm{C}_{16} \mathrm{H}_{11}$ & $\mathrm{C}_{32} \mathrm{H}_{16} \mathrm{O}$ & $\mathrm{C}_{32} \mathrm{H}_{17} \mathrm{O}$ & $\mathrm{C}_{48} \mathrm{H}_{24} \mathrm{O}_{2}$ & $\mathrm{C}_{48} \mathrm{H}_{25} \mathrm{O}_{2}$ \\
\hline$m / z$ & 202.078 & 203.086 & 416.120 & 417.127 & 632.177 & 633.185 \\
Ion form & $\mathrm{M}^{+}$ & {$[\mathrm{M}+\mathrm{H}]^{+}$} & $\mathrm{M}^{+}$ & {$[\mathrm{M}+\mathrm{H}]^{+}$} & $\mathrm{M}^{+}$ & ${ }^{+}$ \\
Chloroform & 2488185 & 1000182 & 352750 & 236336 & 20272 & 14869 \\
Methanol & 12004 & 286349 & 6776 & 317623 & 1321 & 5132 \\
$n$-Hexane & 249585 & 1782453 & 35768 & 406691 & 6011 & 25327 \\
\hline
\end{tabular}


Table 2. Measured Intensities Determined by APPI-QTOF of Different Molecules According to the Solvent and Dopant Used

\begin{tabular}{lcccrrr}
\hline & $\mathrm{C}_{16} \mathrm{H}_{10}$ & $\mathrm{C}_{16} \mathrm{H}_{11}$ & $\mathrm{C}_{32} \mathrm{H}_{16} \mathrm{O}$ & $\mathrm{C}_{32} \mathrm{H}_{17} \mathrm{O}$ & $\mathrm{C}_{48} \mathrm{H}_{24} \mathrm{O}_{2}$ & $\mathrm{C}_{48} \mathrm{H}_{25} \mathrm{O}_{2}$ \\
\hline$m / z$ & 202.078 & 203.086 & 416.120 & 417.127 & 632.177 \\
Ion form & $\mathrm{M}^{+}$ & {$[\mathrm{M}+\mathrm{H}]^{+}$} & $\mathrm{M}^{+}$ & {$[\mathrm{M}+\mathrm{H}]^{+}$} & $\mathrm{M}^{+}$ & 633.185 \\
Chloroform & 72048 & 222808 & 35958 & 62199 & 1813 & {$[\mathrm{M}+\mathrm{H}]^{+}$} \\
Methanol & 3131 & 714 & 15555 & 8395 & 2291 \\
$n$-Hexane & 438037 & 407450 & 181436 & 228023 & 10648 & 1470 \\
Chloroform+toluene & 362820 & 117704 & 421677 & 194047 & 16940 \\
Methanol+toluene & 436436 & 130747 & 499798 & 246669 & 10274 & 5374 \\
$n$-Hexane+toluene & 336042 & 121505 & 425090 & 209581 & 3162 \\
\hline
\end{tabular}

than that of the PAH, the radical $\mathrm{PAH}^{+\bullet}$ is observed. This was the case in our experiments using pyrene (7.42 eV) [25] but such radical was not observed using fluoranthene $(7.9 \mathrm{eV})$, in accordance with Ling and Lifshitz [28].

With the ESI source, the mass spectrum does not show any ion corresponding to $\mathrm{C}_{32} \mathrm{H}_{16} \mathrm{O}$ or $\mathrm{C}_{48} \mathrm{H}_{24} \mathrm{O}_{2}$ even when silver nitrate is used as cationization mediator.

\section{$A P C I$ and APPI Sources}

\section{$A P C I$}

As shown on Table 1, APCI was able to ionize the PAHs and oxy-PAHs present in the reference solution. The highest detection intensity for fluoranthene under its radical ion form $\left(\mathrm{M}^{+}\right)$was obtained with chloroform as solvent. $n$-Hexane and methanol led only to lower intensities. For the protonated form $[\mathrm{M}+\mathrm{H}]^{+}$, the highest intensity was reached using $n$-hexane. Intensity decreased from chloroform to methanol.

For higher molecular mass compounds, such as $\mathrm{C}_{32} \mathrm{H}_{16} \mathrm{O}$, the highest intensity was found for the protonated form $(\mathrm{m} / \mathrm{z} 417)$ using $n$-hexane, followed by methanol and chloroform. The highest intensity for the radical ion $(m / z 416)$ was obtained with chloroform; methanol and $n$-hexane gave very low intensities. In

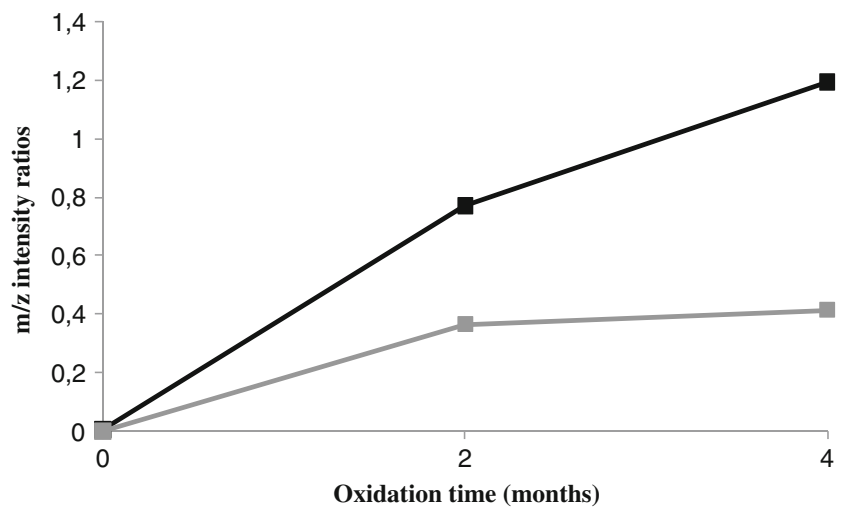

Figure 2. Relative contribution of oxygenated high molecular mass reaction products normalized to unreacted fluoranthene as determined by either APCI-QTOF $\left(-I_{\mathrm{m} / z} 416 / I_{\mathrm{m} / \mathrm{z} 202)}\right.$ or APPI-QTOF $\left(\mathrm{I}_{\mathrm{m} / \mathrm{z}} 416 / \mathrm{I}_{\mathrm{m} / \mathrm{z}}\right.$ 202). The measurements were performed on $\mathrm{CHCl}_{3}$ extracts obtained after oxidation at $100{ }^{\circ} \mathrm{C}$ as a function of time of a fluoranthene/limestone mixture. Oxidation leads to the formation of oxygenated products of molecular masses higher than the initial reactant the case of $\mathrm{C}_{48} \mathrm{H}_{24} \mathrm{O}_{2}$, the highest intensity was found for the protonated form $[\mathrm{M}+\mathrm{H}]^{+}$using $n$-hexane. Intensity values, for ion $\mathrm{m} / \mathrm{z} 633$ were lower and decreased when chloroform and methanol were used for the protonated ion. Considering the radical form $(\mathrm{m} / \mathrm{z}$ 632) intensities decrease as following $\mathrm{I}_{\text {chloroform }}>\mathrm{I}_{n \text {-hexane }}>\mathrm{I}_{\text {methanol }}$.

\section{$A P P I$}

The experiments with APPI were run with and without toluene as dopant, using the same solvents as for APCI ( $n$ hexane, chloroform, and methanol). Results are presented in Table 2. Toluene was preferred because it has low ionization energy $(8.83 \mathrm{eV})$ and it is less harmful to health than benzene or its halogenated derivates. Toluene as dopant was successfully applied to naphthalenes [19].

The highest intensities found for fluoranthene, under both ion forms were found using $n$-hexane. Chloroform, methanol, and $n$-hexane, all with dopant gave similar results when chloroform and methanol gave lower signal more noticeable for methanol (Table 2). For higher molecular mass oxy-PAHs, i.e., $\mathrm{C}_{32}$ compounds, all solvents with dopant gave the highest intensity values. In the absence of dopant, $n$-hexane leads to intensities almost $50 \%$ lower than with dopant, while values for

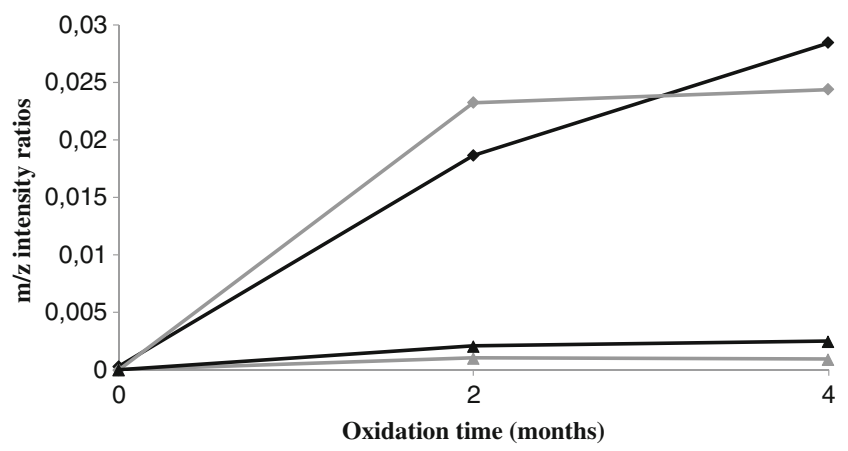

Figure 3. Relative contribution of oxygenated high molecular mass reaction products normalized to unreacted fluoran-

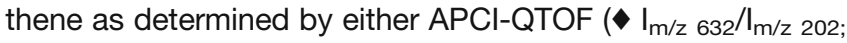

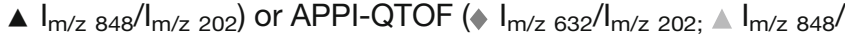

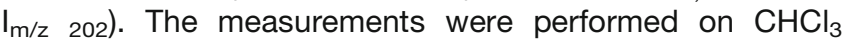
extracts obtained after oxidation at $100{ }^{\circ} \mathrm{C}$ as a function of time of a fluoranthene/limestone mixture. Oxidation leads to the formation of oxygenated products of molecular mass higher than the initial reactant 


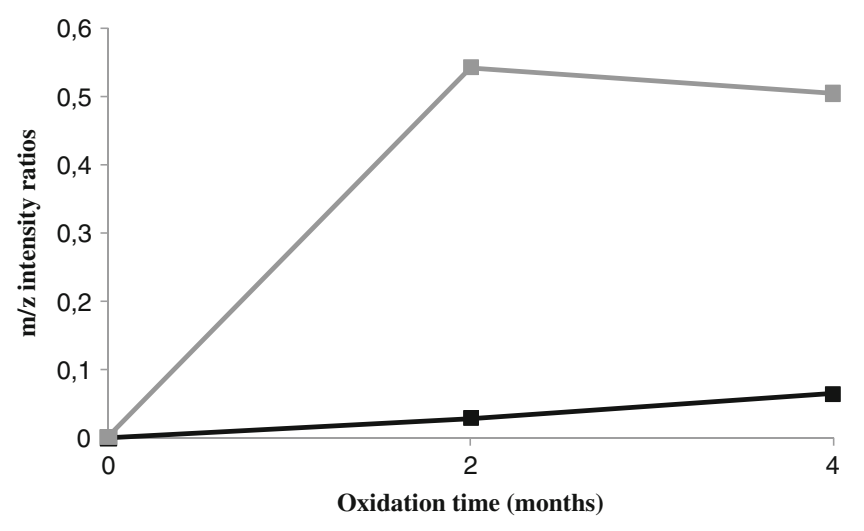

Figure 4. Relative contribution of oxygenated high molecular mass reaction products normalized to unreacted fluoran-

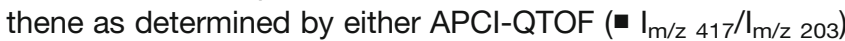
or APPI-QTOF $\left(\mathrm{I}_{\mathrm{m} / \mathrm{z}} 417 / \mathrm{I}_{\mathrm{m} / \mathrm{z}}\right.$ 203). The measurements were performed on $\mathrm{CHCl}_{3}$ extracts obtained after oxidation at $100{ }^{\circ} \mathrm{C}$ as a function of time of a fluoranthene/limestone mixture. Oxidation leads to the formation of oxygenated products of molecular masses higher than the initial reactant

chloroform and methanol were 30 times lower. For the detection of its protonated form $(m / z 417), n$-hexane as well as all solvents with dopant gave similar results. Methanol and chloroform lead to the lowest values.

For $\mathrm{C}_{48} \mathrm{H}_{24} \mathrm{O}_{2}$, the most oxygenated form $(m / z 632)$, the results were in the same range, except for chloroform, methanol, and $n$-hexane+toluene, which gave very low intensities. For the protonated form, using $n$-hexane without dopant gave intensity more than twice that of the others solvents.

\section{Discussion}

Ghislain et al. [4] studied the air oxidation of fluoranthene catalyzed by minerals. Reactions were conducted at $100{ }^{\circ} \mathrm{C}$

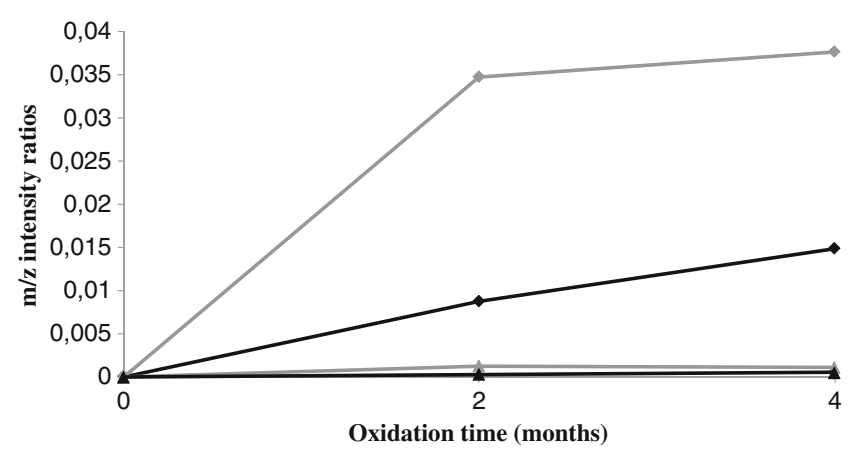

Figure 5. Relative contribution of oxygenated high molecular mass reaction products normalized to unreacted fluoran-

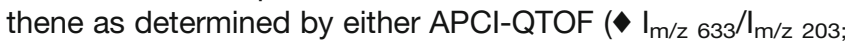

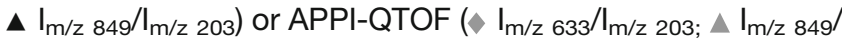

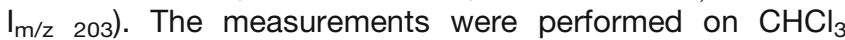
extracts obtained after oxidation at $100{ }^{\circ} \mathrm{C}$ as a function of time of a fluoranthene/limestone mixture. Oxidation leads to the formation of oxygenated products of molecular masses higher than the initial reactant

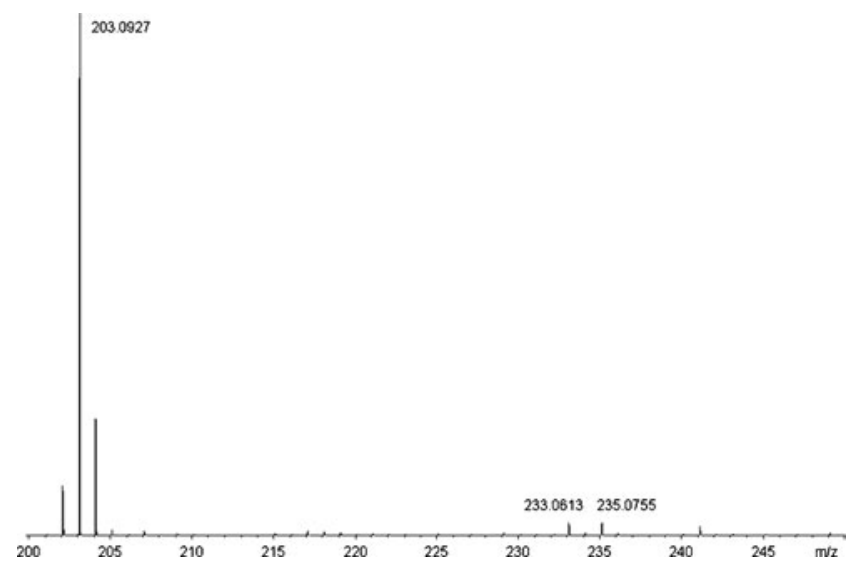

Figure 6. APCl+ mass spectrum within the range $\mathrm{m} / \mathrm{z} 200-$ 250 using hexane

for several hours to months. The compounds in the reference solution of this paper were among the end-products obtained by these reactions. Testing different ionization sources allowed evaluating their incidence on the results, especially their ability in detecting higher molecular mass compounds, which are the major outcome of the reaction studied.

\section{APCI versus APPI versus ESI}

ESI was only able to detect pure $\mathrm{PAH}$ in the $\mathrm{PAH}+$ oxy-PAH mixture and lead to the use of silver ions as cationization mediator. The electrochemical reaction using silver ions was not successful for heavier oxy-PAH as we assume that their ionization energy might be too high for silver mediation.

When APCI is used for the PAH and oxy-PAH mixture studied, the radical ion forms were better detected using chloroform (Table 1). On the contrary best detection of the protonated forms was performed using $n$-hexane. Yet, these differences are reduced concerning the higher molecular mass compounds $\left(\mathrm{C}_{48} \mathrm{H}_{24} \mathrm{O}_{2}\right)$.

In the case of APPI, without consideration of either radical or protonated ions, $n$-hexane gave the best results for fluoranthene

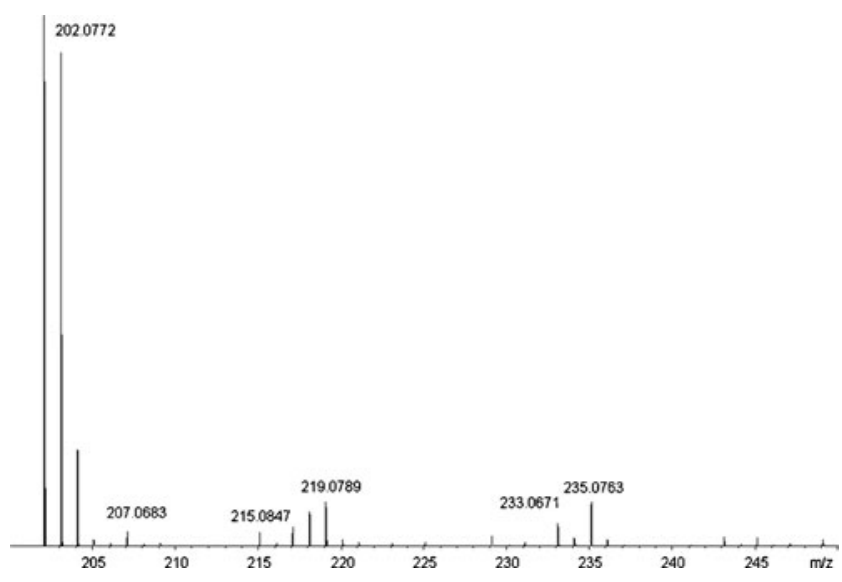

Figure 7. APPI+ mass spectrum within the range $\mathrm{m} / \mathrm{z} 200-$ 250 using hexane 
and $\mathrm{C}_{48} \mathrm{H}_{24} \mathrm{O}_{2}$ detection and acceptable results for $\mathrm{C}_{32} \mathrm{H}_{16} \mathrm{O}$ (Table 2). These results can be explained by the self-doping effects usually observed when using $n$-Hexane [29].

The higher molecular mass compounds $\mathrm{C}_{32} \mathrm{H}_{16} \mathrm{O}(\mathrm{m} / \mathrm{z}$ 416) and $\mathrm{C}_{48} \mathrm{H}_{24} \mathrm{O}_{2}(\mathrm{~m} / \mathrm{z}$ 632), which were not detected using ESI, are clearly identified using APCI and APPI.

\section{APCI Versus APPI}

Q-TOF mass spectrometry is not a quantitative detection method. Thus, the evolution of the reaction products from the oxidation experiments as a function of time was followed up by using intensities ratios between each oxy-PAH (reaction products) and fluoranthene (reactant). APPI and APCI were compared, and ions under radical or protonated forms using $n$-hexane were considered, (Figures 2, 3, 4, and 5). In these experiments, an additional compound was also considered, i.e., $\mathrm{C}_{64} \mathrm{H}_{32} \mathrm{O}_{3}(\mathrm{~m} / z$ 848).

When the molecular ions are considered (Figures 2 and 3 ), a main difference appears in the ratio values nearly $2-3$ times higher for APCI $\left(I_{m / z} 416 / I_{m / z} 202\right)$ than for APPI. However, for the $\mathrm{I}_{m / z} 632 / \mathrm{I}_{m / z} 202$; and $\mathrm{I}_{m / z} 8_{848} / \mathrm{I}_{m / z} 202$, APPI and APCI gave similar results (Figure 3).

When using protonated ion ratios (Figures 4 and 5), the main difference appears for the $\mathrm{I}_{m / z} 417 / \mathrm{I}_{m / z} 203$ ratio values nearly 10 times higher for APPI than for APCI and 3 times higher in the case of $\mathrm{I}_{m / z} 6_{33} / \mathrm{I}_{m / z} 203$. This mainly implies a better detection of fluoranthene using APCI. Ion suppression between fluoranthene and the reaction products seems to be stronger when APCI is used.

On both spectra using APCI and APPI (Figures 6 and 7), it can also be observed that regardless of fluoranthene, more compounds in the intermediate $\mathrm{m} / \mathrm{z} 202$ to 250 range are detected using APPI than APCI.

APPI thus appears as the most suitable ionization source for the compounds studied because:

- it allows the detection of the higher molecular mass compounds $\left(\mathrm{C}_{32} \mathrm{H}_{16} \mathrm{O}\right.$ and $\left.\mathrm{C}_{48} \mathrm{H}_{24} \mathrm{O}_{2}\right)$ not detected by ESI

- it reduces the ionization competition between fluoranthene and the reaction products compared with APCI

- it favors the ionization of the intermediate molecular mass reaction compounds ( $\mathrm{m} / \mathrm{z} 202$ to 250) compared with APCI. These compounds may probably be weakly polar or have low proton affinity, thus not ionized by APCI

All these characteristics led to chosing APPI as ionization source in order to characterize the full extent of reaction products, thus allowing to propose a condensation reaction mechanism during the low temperature oxidation of fluoranthene on mineral matrix [4].

\section{Conclusion}

In our experiments, ESI did not prove to be capable of analyzing the PAHs and oxy-PAHS mixture even with the use of silver ions as cationization mediator. On the contrary, APPI and APCI gave better results using $n$-hexane as solvent, especially in the detection of higher molecular mass compounds $\left(\mathrm{C}_{32} \mathrm{H}_{16} \mathrm{O}\right.$ and $\mathrm{C}_{48} \mathrm{H}_{24} \mathrm{O}_{2}$. APPI was preferentially used without dopant (as $n$-hexane presents self-doping effect).

Yet, concerning the study of our reaction products mixture, the APCI source favored the ionization of fluoranthene (the reactant) compared with the reaction products. This led to ionization competition, which lowered the relative detection of the higher molecular mass compounds in the follow up of the reactions. Also, APCI was less efficient than APPI to detect the intermediate molecular mass range of products (probably weakly polar compounds not favorably ionized by APCI).

The APPI source finally appeared as the most suitable ionization source for the follow up of our reaction products, because it allowed the detection of the full range of compounds from low to high molecular mass. Consequently, it permitted he identification of full series of reaction products that were interpreted as being formed through a polycondensation mechanism [4].

\section{Acknowledgments}

The authors thank François Dupire from the Mass Spectrometry Facility of the Nancy University for the APCI loan. The doctoral grant for T.G. was provided by the Regional Council of Lorraine (France) and CREGU. The Q-TOF instrument was funded by Regional Council of Lorraine and CNRS (CPER 2004).

\section{References}

1. Killops, S.D.: An Introduction to Organic Geochemistry/S.D. Killops, V.J. Killops. Geochemistry series. Killops, V.J. (ed.) Harlow: Essex, England, New York, Longman Scientific and Technical; Wiley (1993)

2. Tissot, B.P., Welte, D.H.: Petroleum Formation and Occurrence, 2 nd ed. pp. 699 Springer Verlag: Berlin; Heidelberg; New York; Tokyo (1984)

3. Marshall, A.G., Kim, D.G., Klein, G.C., Stanford, L.A., Purcell, J.M., Schaub, T.M., Smith, D.F., Hendrickson, C.L., Rodgers, R.P.: Compositional characterization of petroleum by ultrahigh-resolution fourier transform ion cyclotron resonance mass spectrometry with multiple ionization sources - 232nd ACS National Meeting Book of Abstracts (2006)

4. Ghislain, T., Faure, P., Biache, C., Michels, R.: Low-temperature, mineral-catalyzed air oxidation: a possible new pathway for $\mathrm{PAH}$ stabilization in sediments and soils. Environ. Sci. Technol. 44(22), 8547-8552 (2010)

5. Biache, C., Ghislain, T., Faure, P., Mansuy-Huault, L.: Low temperature oxidation of a coking plant soil organic matter and its major constituents: an experimental approach to simulate a long-term evolution. J. Hazard. Mater. 188(1/3), 221-230 (2011)

6. Hand, O.W., Winger, B.E., Cooks, R.G.: Enhanced silver cationization of polycyclic aromatic hydrocarbons containing bay regions in molecular secondary ion mass spectrometry. Biomed. Environ. Mass Spectrom. 18(1), 83-85 (1989) 
7. Moriwaki, H., Ishitake, M., Yoshikawa, S., Miyakoda, H., Alary, J.F.: Determination of polycyclic aromatic hydrocarbons in sediment by liquid chromatography-atmospheric pressure photoionization-mass spectrometry. Anal. Sci. 20(2), 375-377 (2004)

8. Lien, G.W., Chen, C.Y., Wu, C.F.: Analysis of polycyclic aromatic hydrocarbons by liquid chromatography/tandem mass spectrometry using atmospheric pressure chemical ionization or electrospray ionization with tropylium post-column derivatization. Rapid Commun. Mass Spectrom. 21(22), 3694-3700 (2007)

9. Van Berkel, G.J., McLuckey, S.A., Glish, G.L.: Electrochemical origin of radical cations observed in electrospray ionization mass spectra. Anal. Chem. 64(14), 1586-1593 (1992)

10. Van Berkel, G.J., Zhou, F.: chemical electron-transfer reactions in electrospray mass spectrometry: effective oxidation potentials of electron-transfer reagents in methylene chloride. Anal. Chem. 66(20), 3408-3415 (1994)

11. Maziarz III, E.P., Baker, G.A., Wood, T.D.: Electrospray ionization fourier transform mass spectrometry of polycyclic aromatic hydrocarbons using silver(I)-mediated ionization. Can. J. Chem. 83(11), 1871-1877 (2005)

12. Ng, K.M., Ma, N.L., Tsang, C.W.: Differentiation of Isomeric Polyaromatic Hydrocarbons by Electrospray Ag(I) Cationization Mass Spectrometry. Rapid Commun. Mass Spectrom. 17(18), 2082-2088 (2003)

13. Deng, H., Kebarle, P.: Binding energies of silver ion-ligand, L, complexes AgL2 + Determined from ligand-exchange equilibria in the gas phase. J. Phys. Chem. A 102(3), 571-579 (1998)

14. Lafleur, A.L., Taghizadeh, K., Howard, J.B., Anacleto, J.F., Quilliam, M.A.: Characterization of flame-generated c10 to c160 polycyclic aromatic hydrocarbons by atmospheric-pressure chemical ionization mass spectrometry with liquid introduction via heated nebulizer interface. J. Am. Soc. Mass Spectrom. 7(3), 276-286 (1996)

15. Grosse, S., Letzel, T.: Liquid chromatography/atmospheric pressure ionization mass spectrometry with post-column liquid mixing for the efficient determination of partially oxidized polycyclic aromatic hydrocarbons. J. Chromatogr. A 1139(1), 75-83 (2007)

16. Marvin, C.H., Smith, R.W., Bryant, D.W., McCarry, B.E.: Analysis of high-molecular-mass polycyclic aromatic hydrocarbons in environmental samples using liquid chromatography-atmospheric pressure chemical ionization mass spectrometry. J. Chromatogr. A 863(1), 13-24 (1999)

17. Cai, S.-S., Syage, J.A., Hanold, K.A., Balogh, M.P.: Ultra performance liquid chromatography-atmospheric pressure photoionization-tandem mass spectrometry for high-sensitivity and high-throughput Analysis of U.S. Environmental Protection Agency 16 priority pollutants polynuclear aromatic hydrocarbons. Anal. Chem. 81(6), 2123-2128 (2009)

18. Short, L.C., Cai, S.S., Syage, J.A.: APPI-MS: effects of mobile phases and VUV lamps on the detection of PAH compounds. J. Am. Soc. Mass Spectrom. 18(4), 589-599 (2007)

19. Kauppila, T.J., Kuuranne, T., Meurer, E.C., Eberlin, M.N., Kotiaho, T., Kostiainen, R.: Atmospheric pressure photoionization mass spectrometry. ionization mechanism and the effect of solvent on the ionization of naphthalenes. Anal. Chem. 74(21), 5470-5479 (2002)

20. Smith, D.R., Robb, D.B., Blades, M.W.: Comparison of dopants for charge exchange ionization of nonpolar polycyclic aromatic hydrocarbons with reversed-phase LC-APPI-MS. J. Am. Soc. Mass. Spectrom. 20(1), 73-79 (2009)

21. Robb, D.B., Smith, D.R., Blades, M.W.: Investigation of substitutedbenzene dopants for charge exchange ionization of nonpolar compounds by atmospheric pressure photoionization. J. Am. Soc. Mass Spectrom. 19(7), 955-963 (2008)

22. Kauppila, T.J., Bruins, A.P., Kostiainen, R.: Effect of the solvent flow rate on the ionization efficiency in atmospheric pressure photoionization-mass spectrometry. J. Am. Soc. Mass Spectrom. 16(8), 1399-1407 (2005)

23. Kebarle, P.: A brief overview of the present status of the mechanisms involved in electrospray mass spectrometry. J. Mass Spectrom. 35(7), 804-817 (2000)

24. Kebarle, P., Tang, L.: From ions in solution to ions in the gas phasethe mechanism of electrospray mass spectrometry. Anal. Chem. 65(22), 972A-986A (1993)

25. Hager, J.W., Wallace, S.C.: Two-laser photoionization supersonic jet mass spectrometry of aromatic molecules. Anal. Chem. 60(1), 5-10 (1988)

26. Shenstone, A.G.: The arc spectrum of silver. Phys. Rev. 57(10), 894898 (1940)

27. Loock, H.P., Beaty, L.M., Simard, B.: Reassessment of the first ionization potentials of copper, silver, and gold. Phys. Rev. A: At. Mol. Opt. Phys. 59(1), 873-875 (1999)

28. Ling, Y., Lifshitz, C.: Time-dependent mass spectra and breakdown graphs. 19. Fluoranthene. J. Phys. Chem. 99(28), 11074-11080 (1995)

29. Cai, S.S., Hanold, K.A., Syage, J.A.: Comparison of atmospheric pressure photoionization and atmospheric pressure chemical ionization for normal-phase LC/MS chiral analysis of pharmaceuticals. Anal. Chem. 79(6), 2491-2498 (2007) 